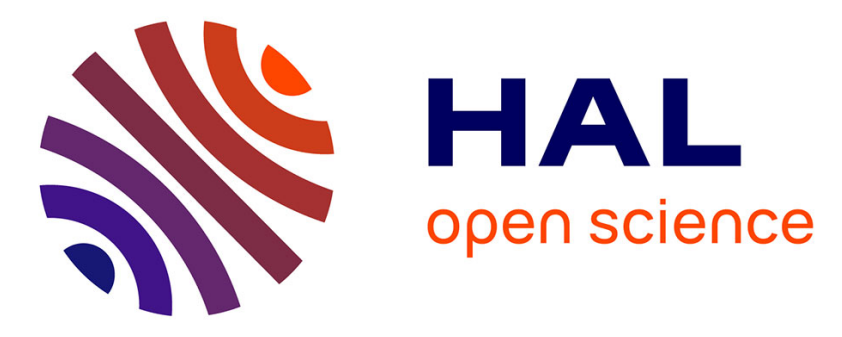

\title{
Effect of Head-to-Head Addition in Vinyl Acetate Controlled Radical Polymerization: Why Is Co(acac) 2 -Mediated Polymerization so Much Better?
}

Aurélie Morin, Christophe Detrembleur, Christine Jérôme, Pascal de Tullio, Rinaldo Poli, Antoine Debuigne

\section{To cite this version:}

Aurélie Morin, Christophe Detrembleur, Christine Jérôme, Pascal de Tullio, Rinaldo Poli, et al.. Effect of Head-to-Head Addition in Vinyl Acetate Controlled Radical Polymerization: Why Is Co(acac) 2 -Mediated Polymerization so Much Better?. Macromolecules, 2013, 46 (11), pp.4303-4312. 10.1021/ma400651a . hal-02908272

\section{HAL Id: hal-02908272 \\ https://hal.science/hal-02908272}

Submitted on 2 Mar 2021

HAL is a multi-disciplinary open access archive for the deposit and dissemination of scientific research documents, whether they are published or not. The documents may come from teaching and research institutions in France or abroad, or from public or private research centers.
L'archive ouverte pluridisciplinaire HAL, est destinée au dépôt et à la diffusion de documents scientifiques de niveau recherche, publiés ou non, émanant des établissements d'enseignement et de recherche français ou étrangers, des laboratoires publics ou privés. 


\section{Effect of head-to-head addition in vinyl acetate}

\section{controlled radical polymerization: why is $\mathrm{Co}(\mathrm{acac})_{2-}$}

\section{mediated polymerization so much better?}

Aurélie N. Morin, ${ }^{+, \neq}$Christophe Detrembleur, ${ }^{\circledR}$ Christine Jérôme, ${ }^{\llbracket}$ Pascal De Tullio, ${ }^{\ddagger}$ Rinaldo

Poli, ${ }^{*},+,+$, \& Antoine Debuigne, $*$ ॠ

${ }^{\dagger}$ CNRS, LCC (Laboratoire de Chimie de Coordination), 205 Route de Narbonne, BP 44099, F-

31077 Toulouse Cedex 4, France CNRS.

‡Université de Toulouse, UPS, INPT, F-31077 Toulouse Cedex 4, France.

$\S$ Institut Universitaire de France, 103, bd Saint-Michel, 75005 Paris, France.

" Center for Education and Research on Macromolecules (CERM), Chemistry Department, University of Liège (ULg), Sart-Tilman, B6a, 4000 Liège, Belgium.

${ }^{\mathfrak{E}}$ Drug Reserch Center (CIRM), Laboratory of Medicinal Chemistry , University of Liège (ULg), 1 avenue de l'Hopital, 4000 Sart-Tilman.

KEYWORDS: vinyl acetate; controlled radical polymerization; DFT calculations; ATRP;

OMRP; CMRP; ITP; RAFT/MADIX; TERP; head-to-head addition. 
ABSTRACT. The controlled polymerization of vinyl acetate has been recently achieved by several techniques, but PVAc with targeted $M n$ and low dispersity up to very high monomer conversions and high degrees of polymerization was only obtained with $\mathrm{Co}(\mathrm{acac})_{2}$ as controlling agent in the so-called CMRP, a type of organometallic mediated radical polymerization (OMRP). Other techniques (including ATRP, ITP, TERP and RAFT/MADIX) have shown a more or less pronounced slowdown in the polymerization kinetics, which was attributed to the higher strength of the $\mathrm{C}-\mathrm{X}$ bond between the radical PVAc chain and the trapping agent (X) in the dormant species and to a consequent slower reactivation after a less frequent head-to-head monomer addition. The reason for the CMRP exception is clarified by the present contribution. First, a detailed investigation by ${ }^{1} \mathrm{H},{ }^{13} \mathrm{C}$ and multiplicity-edited HSQC and DEPT-135 NMR of the PVAc obtained by CMRP, in comparison with a regular polymer made by free radical polymerization under the same conditions, has revealed that $\mathrm{Co}(\mathrm{acac})_{2}$ does not significantly alter the fraction of head-to-head sequences in the polymer backbone and that there is no accumulation of $\mathrm{Co}(\mathrm{acac})_{2}$-capped chains with a head-to-head $\omega$ end. Hence, both dormant chains (following the head-to-head and the head-to-tail monomer additions) must be reactivated at similar rates. A DFT study shows that this is possible because the dormant chains are stabilized not only by the C-Co $\sigma$ bond but also by formation of a chelate ring through coordination of the $\omega$ monomer carbonyl group. The head-to-head dormant chain contains an inherently stronger C-Co bond but forms a weaker 6-membered chelate ring, whereas the weaker C-Co bond in the head-to-tail dormant chain is compensated by a stronger 5-membered chelate ring. Combination of the two effects leads to similar activation enthalpies, as verified by DFT calculations using a variety of local, gradient-corrected, hybrid and "ad hoc" functionals (BPW91, B3PW91, BPW91*, M06 and M06L). While the BDE(C-X) of model H-VAc-X 
molecules $\left[\mathrm{X}=\mathrm{Cl}\right.$, I, MeTe, $\operatorname{EtOC}(\mathrm{S}) \mathrm{S}$ and $\left.\mathrm{Co}(\mathrm{acac})_{2}\right]$ are functional dependent, the $\mathrm{BDE}$ difference between head-to-head and head-to-tail dormant chain models is almost functional insensitive, with values of 5-9 $\mathrm{kcal} / \mathrm{mol}$ for the ATRP, ITP and TERP models, 3-6 for the RAFT/MADIX model, and around zero for CMRP. 


\section{Introduction}

Poly(vinyl acetate) (PVAc) is a large scale market polymer ( $>1$ million tons/yr) with multiple applications as an adhesive emulsions, as a protective coating and especially as a raw material to make other polymers like poly(vinyl alcohol) and poly(vinyl acetate phthalate) that have many important application of their own. ${ }^{1}$ It can only be produced by the radical route, although copolymers with limited incorporation of vinyl acetate monomer have recently been accessed by coordination polymerization. $^{2}$

The implementation of controlled radical polymerization (CRP) techniques has revolutionized polymer chemistry because structurally organized macromolecular architectures with controlled dimensions, low molecular weight dispersity and precisely located functionalities have become accessible. This opens the way to a multitude of new smart functional materials for advanced applications. ${ }^{3}$ The possibility to control the polymerization of VAc has attracted a great deal of attention because of the large variety of conceivable new materials that could potentially be obtained by incorporating PVAc blocks, particularly amphiphilic structures resulting from hydrolysis to poly(vinyl alcohol). Satisfactory control, however, has not been achieved for the majority of the techniques so far applied to the CRP of VAc. 
Table 1. Reported systems for the CRP of VAc and characteristics of the resulting polymer.

\begin{tabular}{|c|c|c|c|c|c|c|c|}
\hline Entry & Method & Controlling system & Initiator & $X_{n}{ }^{\mathrm{a}}$ & $\oplus^{\mathrm{a}}$ & remarks & Ref. \\
\hline 1 & ATRP (?) & $\mathrm{Fe}(\mathrm{OAc})_{2} / \mathrm{PMDETA}^{\mathrm{b}}$ & $\mathrm{CCl}_{4}$ & $\sim 170$ & $\sim 2$ & Telomerization by transfer to $\mathrm{CCl} 4$ & 4,5 \\
\hline 2 & ATRP & {$\left[\mathrm{CpFe}(\mathrm{CO})_{2}\right]_{2} / \mathrm{M}(\mathrm{O} i \mathrm{Pr})_{\mathrm{n}}$} & $\left(\mathrm{CH}_{3}\right)_{2} \mathrm{C}\left(\mathrm{CO}_{2} \mathrm{Et}\right) \mathrm{I}$ & $\sim 120$ & $\sim 2$ & Slowdown, max. conv. $=60 \%$ & 6 \\
\hline 3 & ATRP & $\mathrm{CuCl} / \mathrm{PMDETA}{ }^{\mathrm{b}}$ & $\mathrm{CH}_{3} \mathrm{CH}\left(\mathrm{CO}_{2} \mathrm{Me}\right) \mathrm{Br}$ & 7.5 & 1.6 & Stopped at $14 \%$ conversion & 5 \\
\hline 4 & ATRP & $\mathrm{CuCl}$ or $\mathrm{CuBr} /$ terpy $^{\mathrm{c}}$ & $\left(\mathrm{CH}_{3}\right)_{2} \mathrm{C}\left(\mathrm{CO}_{2} \mathrm{Et}\right) \mathrm{Br}$ & $\sim 120$ & 1.7 & Linear first-order plot ( $\sim 75 \%$ conv.) & 7 \\
\hline 5 & RAFT & $\mathrm{Ph}_{2} \mathrm{NC}(\mathrm{S}) \mathrm{SCH}\left(\mathrm{CO}_{2} \mathrm{Et}\right)_{2}$ & AIBN & 57 & 1.56 & $Ð$ increases with conv. (up to $73 \%$ ) & 8 \\
\hline 6 & RAFT & $\mathrm{EtOC}(\mathrm{S}) \mathrm{SCH}_{2} \mathrm{CN}$ & AIBN & $\sim 127$ & 1.31 & Linear first-order plot ( $77 \%$ conv.) & 9 \\
\hline 7 & RAFT & $\mathrm{EtOC}(\mathrm{S}) \mathrm{SCH}_{2} \mathrm{CO}_{2} \mathrm{Me}$ & AIBN & $\sim 580$ & 1.18 & $Ð$ at $25 \%$ conv. ( $\max . \operatorname{conv} \sim 56 \%$ ) & 10 \\
\hline 8 & ITP & $\mathrm{CH}_{3} \mathrm{CH}\left(\mathrm{CO}_{2} \mathrm{Et}\right) \mathrm{I}$ & $\mathrm{CPD}^{\mathrm{d}}$ & $\sim 400$ & 1.45 & Slowdown, $\max$. conv. $=57 \%$ & 11 \\
\hline 9 & TERP & $\left(\mathrm{CH}_{3}\right)_{2} \mathrm{C}\left(\mathrm{CO}_{2} \mathrm{Et}\right) \mathrm{TeMe}$ & AIBN & 34 & 1.28 & Slowdown at low conversions & 12 \\
\hline 10 & OMRP & \multicolumn{2}{|c|}{$\mathrm{R}_{0}-\left(\mathrm{CH}_{2} \mathrm{CHOAc}\right)_{<4}-\mathrm{Co}(\mathrm{acac})_{2}{ }^{\mathrm{e}}$} & $\sim 1630$ & 1.27 & Linear first-order plot (52\% conv.) & 13 \\
\hline 11 & OMRP & \multicolumn{2}{|c|}{$\mathrm{CpCr}($ nacnac $)\left(\mathrm{CH}_{2} t \mathrm{Bu}\right)^{\mathrm{f}}$} & 175 & 1.46 & Slowdown, $\max$ conv. $=14 \%$ & 14 \\
\hline 12 & OMRP & $(\mathrm{TMP}) \mathrm{Co}^{\mathrm{g}}$ & AIBN & $\sim 660$ & 1.27 & Max conv. $=10 \%$ & 15 \\
\hline
\end{tabular}

${ }^{\mathrm{a}}$ Highest reported number average degree of polymerization $\left(X_{n}\right)$ and dispersity $\left(\bigoplus=M_{w} / M_{n}\right)$ at maximum conversion. ${ }^{\mathrm{b}}$ PMDETA $=$ pentamethyldiethylenetriamine. ${ }^{\mathrm{c}}$ terpy $=2,2^{\prime} ; 6^{\prime}, 2^{\prime \prime}$-terpyridine. ${ }^{\mathrm{d}} \mathrm{CPD}=\alpha$-cumyl peroxyneodecanoate. ${ }^{\mathrm{e}} \mathrm{R}_{0}=$ initiating fragment of $\mathrm{V70}=2,2^{\prime}$-Azobis(4-methoxy-2.4-dimethyl valeronitrile). ${ }^{\mathrm{f}}$ nacnac $=\operatorname{ArNC}(\mathrm{Me}) \mathrm{CHC}(\mathrm{Me}) \mathrm{NAr}\left(\mathrm{Ar}=2,6-\mathrm{C}_{6} \mathrm{H}_{3} \mathrm{Me}_{2}\right) .{ }^{\mathrm{g}} \mathrm{TMP}=$ tetramesitylporphyrin. 
Table 1 shows the characteristics of the PVAc obtained by a few of the relevant contributions. The most interesting indicators for our purposes are the length of the polymer chain (as expressed by the number average degree of polymerization, $\left.X_{n}\right)$ and the dispersity $\left(\nexists=M_{w} / M_{n}\right)$. For entry 1, the metal system serves as an irreversible atom transfer initiator. The polymerization continues as a telomerization with chain transfer to $\mathrm{CCl}_{4}$ and $M_{n}$ does not grow linearly with conversion. ${ }^{4}$ The first reported ATRP process (although contribution of ITP was suspected) is based on an iron catalyst (entry $2 ; \mathrm{M}=\mathrm{Al}, \mathrm{n}=3 ; \mathrm{M}=\mathrm{Ti}, \mathrm{n}=4),{ }^{6}$ whereas copper-catalyzed ATRP is generally unsuccessful (entry 3$)^{5}$ except for the terpyridine $\mathrm{Cu}^{\mathrm{I}}$ halide system (entry 4 ). ${ }^{7}$ The RAFT method is efficient only with alkyl dithiocarbamate or xanthate transfer agents, particularly the latter for which the acronym MADIX is also frequently used (entries 5-7), ${ }^{8,10,16-18}$ whereas dithioesters, trithiocarbonates and aromatic dithiocarbamates lead to strong inhibition. Iodine transfer polymerization has also allowed controlled growth of PVAc chains (entry 8), ${ }^{11}$ which was however affected by chain end decomposition processes. By TERP (entry 9), the VAc polymerization slowed down and was eventually inhibited at low monomer conversion providing only PVAc with low degrees of polymerization. ${ }^{12}$ Only OMRP using $\mathrm{Co}(\mathrm{acac})_{2}$ as controlling agent ${ }^{13,19-28}$ leads to chain growth that remains well controlled up to very high degrees of polymerization and high conversions (entry 10). ${ }^{13}$ This technique, also called CMRP, also efficiently controls the polymerization of other non-activated monomers including $\mathrm{N}$ vinylamides, ${ }^{29} \mathrm{~N}$-vinylimidazolium ${ }^{30}$ and vinyl chloride. ${ }^{31}$ In many of the other cases, including OMRP with other metal complexes (e.g. entry 11), ${ }^{14}$ the polymerization of vinyl acetate slows down or stops completely before all monomer is consumed and the resulting polymers show higher dispersity, often increasing with conversion. Of note is also the tetramesitylporphyrin system (TMP)Co (entry 12), which leads to a PVAc of relatively high molecular weight and low 
dispersity making use of the degenerate transfer approach, but only low conversions were achieved. $^{15}$

Among many reasons that have been advanced to rationalize these difficulties, some of them valid only for a specific technique (e.g. ATRP), others of general applicability, are the low equilibrium constant for the activation process from the dormant species, the decomposition of the dormant species, the oxidation of the growing radicals to carbocations, the chain transfer to solvent or to polymer. The reactive growing radical of PVAc indeed forms stronger bonds to capping agents relative to more stabilized radicals that are associated to easily controlled monomers such as acrylic or methacrylic monomers and styrenics. ${ }^{32,33}$ For instance, the C-Cl $\mathrm{BDE}$ in $\mathrm{H}-\left(\mathrm{CH}_{2}-\mathrm{CHOAc}\right)-\mathrm{Cl}$, model of the ATRP dormant chain of PVAc, is ca. $10 \mathrm{kcal} / \mathrm{mol}$ stronger than in the isomeric $\mathrm{H}-\left(\mathrm{CH}_{2}-\mathrm{CHCOOMe}\right)-\mathrm{Cl}$, model of the ATRP dormant chain of PMA. $^{32}$ This is the main reason justifying the fact that VAc has always been considered as a "difficult" monomer for CRP. Nevertheless, sufficiently active systems have been developed as shown in Table 1.

However, limitations in the level of control for VAc radical polymerization have also been attributed to the formation of a stronger PVAc-CHOAc- $\mathrm{CH}_{2}-\mathrm{X}$ bond in the dormant species following the inverted monomer insertion by head-to-head addition, which gives a more reactive primary radical. The stronger bond formed by this radical with the trapping agent makes the new dormant species more difficult to reactivate, rationalizing the slowdown of the reaction and the increase of the dispersity index with conversion. The degree of head-to-head addition in VAc polymerization was shown to be small but significant, and to increase with temperature: from about $1.23 \%$ at $25^{\circ} \mathrm{C}$ to $1.95 \%$ at $110^{\circ} \mathrm{C} .{ }^{34}$ Hence, for a suitable system in terms of activation/deactivation equilibrium for the weaker latent secondary radical, it is reasonable to 
expect control at low conversions, but accumulation of the stronger latent primary radicals at higher conversions slows down the polymerization and broadens the molecular weight distribution.

Although this explanation seems reasonable, it does not answer the question why the slowdown is more accentuated for certain systems (e.g. TERP, ATRP with certain $\mathrm{Cu}$ complexes) than for others (e.g. RAFT/MADIX) and especially why doesn't the OMRP system using $\mathrm{Co}(\mathrm{acac})_{2}$ suffer from any slowdown at all. It is notable that $Ð$ remains quite low for this system, whereas other systems, for which a slowdown was not observed or was not reported, show poorer control as suggested by the polymer higher $\oslash$. Thus, either $\operatorname{Co}(\operatorname{acac})_{2}$ is able to somewhat alter the radical reactivity by reducing the incidence of the head-to-head additions, or the dormant species must allow facile reactivation of the latent primary radical.

In order to answer these questions, we have carried out experimental investigations on the PVAc obtained by $\mathrm{Co}(\mathrm{acac})_{2}$-mediated radical polymerization and computational investigations on models of both types of PVAc-Co(acac $)_{2}$ dormant chains, generated by trapping the primary and the secondary radicals. In order to gain a comprehensive view of the effect of this monomer inversion in CRP, we have also calculated the relative bond strengths for the other R-X bonds in the dormant species generated by ATRP, RAFT/MADIX, ITP and TERP.

\section{Results and discussion}

\section{(a) NMR analysis of PVAc}

In this section, we present a detailed NMR investigation of the microstructure of PVAc samples prepared by an OMRP process based on the reversible deactivation of the growing polymer chains with $\mathrm{Co}(\mathrm{acac})_{2}$, specifically tracking the head-to-head units. In this way, we wish 
to evaluate the level and the impact on CMRP of this inverted addition mode, which is the suspected origin of a detrimental effect on the course of other CRPs of VAc as detailed in the introduction. Scheme 1 represents both the major regular head-to-tail $(\mathrm{H}-\mathrm{T})$ addition and the possible inverted head-to-head $(\mathrm{H}-\mathrm{H})$ addition mode in CMRP and their corresponding $\mathrm{CH}_{2} \mathrm{CH}(\mathrm{OAc})-\mathrm{Co}(\mathrm{acac})_{2}$ and $-\mathrm{CH}(\mathrm{OAc}) \mathrm{CH}_{2}-\mathrm{Co}(\mathrm{acac})_{2}$ dormant species.

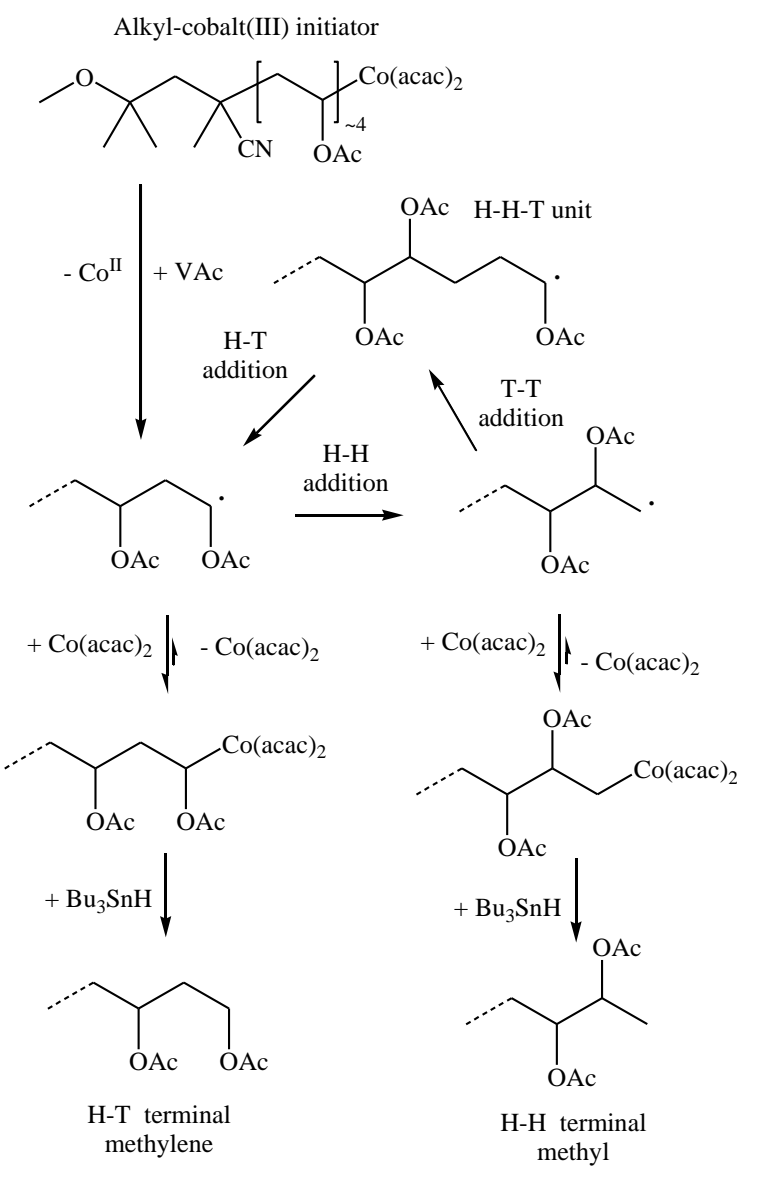

Scheme 1. Head-to-tail (H-T) and head-to-head (H-H) additions in CMRP.

The synthetic conditions and characteristics of the PVAc samples considered in this work are summarized in Table 2. A well-established CMRP procedure was used for the production of the PVAc samples 1 and 2 (PVAc-1 and PVAc-2), which consists of initiation in bulk at $40^{\circ} \mathrm{C}$ from 
a preformed alkyl-cobalt(III) terminated PVAc oligomer (see details in SI). Under these conditions, the CMRP proceeds only via a reversible-termination pathway, guaranteeing the highest level of control for the polymerization. ${ }^{13}$ Relatively low and high molar masses were targeted by adjusting the $[\mathrm{VAc}]_{0} /\left[\mathrm{RCo}(\mathrm{acac})_{2}\right]_{0}$ ratio in order to better appreciate by NMR the chain-end moieties and the defect along the backbone, respectively. In both cases, the molar masses of the final polymers determined by SEC were close to the theoretical predictions and the molar mass distributions were low $(\mathrm{P}=1.04$ and 1.17). A monomer conversion of $30 \%$ was deliberately targeted to preserve as far as possible the integrity of the chain-end. Inspired from a purification procedure described for polymers prepared by TERP, ${ }^{12}$ an excess of tributyltin hydride $\left(\mathrm{Bu}_{3} \mathrm{SnH}\right)$ was injected into the crude CMRP mixture in order to reduce the terminal Co$\mathrm{C}$ bond (see Scheme 1). Following this reaction, the H-T dormant adduct should lead to a terminal methylene $-\mathrm{CH}_{2}-\mathrm{CH}_{2} \mathrm{OAc}$ moiety whereas a terminal methyl group $-\mathrm{CHOAc}-\mathrm{CH}_{3}$ should form upon reduction of the $\mathrm{H}-\mathrm{H}$ dormant species. PVAc-1 and PVAc-2 were also carefully purified by several precipitations in order to remove all traces of cobalt complexes that could alter the quality of the NMR spectra, as well as the residual monomer that is likely to mask signals of interest. For the sake of comparison, we have also prepared a PVAc sample by free radical polymerization (FRP) under similar conditions, i.e. in bulk at $40^{\circ} \mathrm{C}$ (PVAc-3 in Table 2). V-70 was chosen as initiator in order to keep the same $\alpha$-chain end as PVAc-1 and 2. Expectedly, we recovered a PVAc characterized by a high molar mass $\left(\sim 90000 \mathrm{~g} \mathrm{~mol}^{-1}\right)$ and broad molar mass distribution $(\mathrm{\Theta}=2.85)$. 
Table 2. Free and cobalt-mediated radical polymerization of vinyl acetate. ${ }^{a}$

\begin{tabular}{|c|c|c|c|c|c|c|c|c|}
\hline PVAc sample & initiator & {$[\mathrm{VAc}]_{0} /[\text { initiator }]_{0}$} & Time $(\mathrm{h})$ & Conv. $(\%)^{b}$ & $M_{n, \text { th }}\left(\mathrm{g} \cdot \mathrm{mol}^{-1}\right)^{\mathrm{c}}$ & $\begin{array}{l}M_{n, \mathrm{SEC}} \\
\left(\mathrm{g} \cdot \mathrm{mol}^{-1}\right)^{\mathrm{d}}\end{array}$ & $\mathrm{Ð}^{\mathrm{e}}$ & $\begin{array}{l}M_{n, \mathrm{NMR}} \\
\left(\mathrm{g} \cdot \mathrm{mol}^{-1}\right)^{\mathrm{f}}\end{array}$ \\
\hline 1 & $\mathrm{R}-\mathrm{Co}(\mathrm{acac})_{2} \mathrm{~g}$ & 257 & 0.5 & 27 & 6000 & 6700 & 1.04 & 5400 \\
\hline 2 & $\mathrm{R}-\mathrm{Co}(\mathrm{acac})_{2}^{\mathrm{g}}$ & 2010 & 10 & 28 & 48500 & 51100 & 1.17 & 46000 \\
\hline 3 & $\mathrm{~V}-70$ & 166 & 1.5 & 48 & / & 87000 & 2.85 & / \\
\hline
\end{tabular}


The structure of these PVAc samples was investigated using NMR spectroscopy, looking for possible differences in the amount of $\mathrm{H}-\mathrm{H}$ units in the polymers prepared by CMRP and FRP. This technique has already been used to detect defects in PVAc ${ }^{35,36}$ but also in the corresponding poly(vinyl alcohol) $(\mathrm{PVOH})$ produced by hydrolysis of the pendant ester groups. ${ }^{37} \mathrm{We}$ opted to analyze the PVAc samples directly in order to avoid the increase of complexity caused by possible partial hydrolysis or by the possible polymer contamination by the reactants and sideproducts inherent to this additional transformation step. Working on untransformed poly(vinyl acetate)s also permits preserving and quantifying the branches resulting from the principal chain transfer reaction to polymer which proceeds via $\mathrm{H}$-abstraction from the methyl side group. ${ }^{35} \mathrm{H}$ abstraction of a backbone tertiary hydrogen atom is another chain transfer reaction but its contribution to branching is very limited in PVAc, in contrast to polyacrylates. ${ }^{38}$

${ }^{1} \mathrm{H},{ }^{13} \mathrm{C}$, Heteronuclear Single Quantum Correlation (HSQC) and Distortionless Enhancement by Polarisation Transfer (DEPT) analyses were performed on the PVAc samples. For the sake of clarity, all structures susceptible to be present in our samples are drawn in Chart 1 and the atoms with characteristic resonances are labeled for the NMR assignments. The chemical shifts measured in this study and the assignments made on the basis of previous work ${ }^{35,36}$ are provided as supporting information in Table S1. First, the low molar mass PVAc-1 produced by CMRP was characterized by ${ }^{1} \mathrm{H}$ and HSQC (Figure 1) in order to highlight any abnormal accumulation of $\mathrm{H}-\mathrm{H}$ units at the chain-ends, as was the case in the VAc polymerization by TERP. ${ }^{12}$ In the latter case, $58 \%$ of the primary H-H-TeMe adduct were detected by NMR at the PVAc $\omega$-chainend for a polymer with an average $X_{n}$ of $34 .{ }^{12}$ The accumulation of this inverted dormant species at the chain extremity was explained by an exchange constant $\left(\mathrm{C}_{\mathrm{ex}}\right)$ about one hundred times lower than that of the regular secondary H-T-TeMe compound. Besides the peaks corresponding 
to the main chain, i.e. methine a, methylene $\mathbf{b}$ and methyl $\mathbf{c}$, smaller peaks in Figure 1 could be assigned to the methoxy group characteristic of the V-70 initiating fragment $\mathbf{g}\left(\delta_{\mathrm{H}} 3.17\right.$ and $\delta_{\mathrm{C}}$ 48.9) present at the $\alpha$-end of the polymer. Based on the ratio of the area integration of peaks a and $\mathbf{g}$, we determined an average molar mass of $5400 \mathrm{~g} \mathrm{~mol}^{-1}$ which is close to the theoretical value and to the value determined by SEC (see Table 2). It is noteworthy that the monomer conversion, which is close to $30 \%$ for the synthesis of PVAc-1, is not a crucial parameter in this study since the level of inverted VAc addition (about 1.2-1.4 mol\%) is independent on the monomer conversion). ${ }^{35}$ In fact, only the degree of polymerization $\left(X_{n}\right)$ matters and must be high enough to detect a hypothetical abnormal accumulation of stable head-to-head adducts at the PVAc chain-ends. This criterion is fulfilled by PVAc-1 the degree of polymerization of which $\left(X_{n}=62\right)$ is higher compared to the polymer formed by TERP $\left(X_{n}=34\right.$, exhibiting $58 \%$ of H-HTe terminated chains). ${ }^{12}$ In agreement with previous reports, ${ }^{35,36}$ signals e $\left(\delta_{\mathrm{H}} 4.08\right.$ and $\left.\delta_{\mathrm{C}} 60.5\right)$ and $\mathbf{f}\left(\delta_{\mathrm{H}} 1.88\right.$ and $\left.\delta_{\mathrm{C}} 33.6\right)$ were assigned to the terminal methylene moiety and to the penultimate methylene group at the $\omega$-end, respectively. Given the relatively low degree of polymerization of PVAc-1 $\left(X_{n}=62\right)$, it is reasonable to assume that the large majority of the terminal methylene groups results from the reduction by $\mathrm{Bu}_{3} \mathrm{SnH}$ of the normal terminal H-Tcobalt adduct rather than from $\mathrm{H}$-abstraction reaction on the polymer chain leading to branching. Indeed, the level of branching in a PVAc prepared by FRP is typically in the range of $0.1 \mathrm{~mol} \%{ }^{35}$ whereas $1.6 \mathrm{~mol} \%$ of $\omega$-chain ends are present in PVAc- 1 . Hence, the almost perfect $3 / 2$ intensity ratio observed on the ${ }^{1} \mathrm{H}$ spectrum between signals $\mathbf{f}$ and $\mathbf{e}$ suggests that all chains are $\omega$ terminated by the methylene group typical of the regular H-T addition. On the other hand, signals $\mathbf{q}$ and $\mathbf{r}$ (expected at about $\delta 4.7$ and 1.4, respectively), corresponding to the terminal H-H unit, could not be detected, confirming the extremely low level of these species at the $\omega$-chain- 
end of the PVAc formed by CMRP, if any. This situation is therefore in clear contrast with the analysis of the PVAc formed by TERP. The excellent agreement between experimental data and the expected relative intensity for the $\alpha / \omega$-chain-ends also proves the high efficiency of the reduction step involving $\mathrm{Bu}_{3} \mathrm{SnH}$ and the high integrity of the PVAc-Co(acac $)_{2}$ chain-end before its transformation.
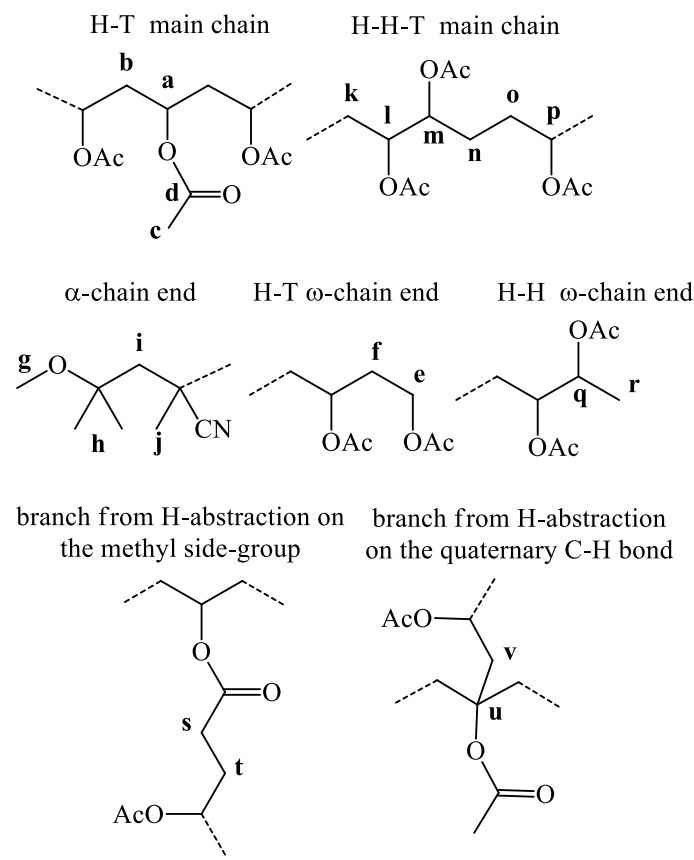

Chart 1. Labeling of typical structures of PVAc.

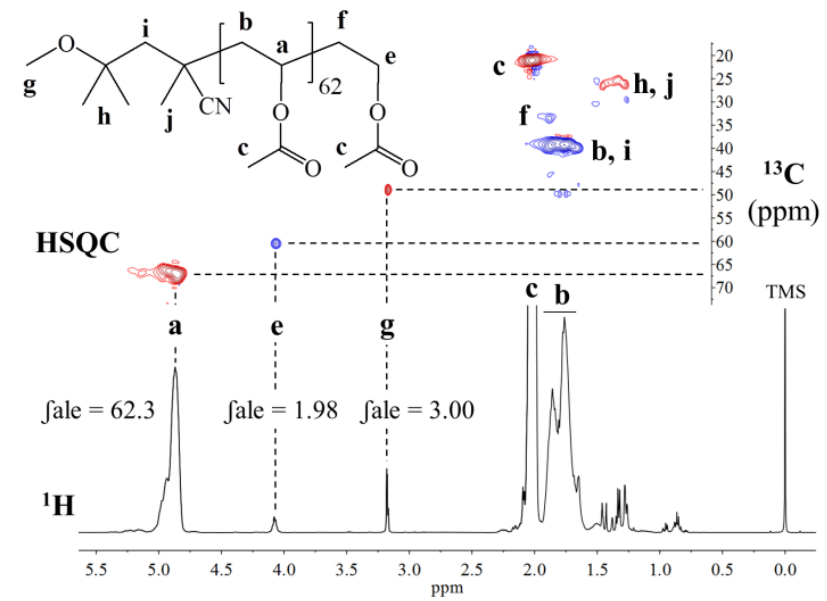


Figure 1. Overlay of ${ }^{1} \mathrm{H}$ and ${ }^{1} \mathrm{H}-{ }^{13} \mathrm{C}$ multiplicity-edited HSQC using Echo/Antiecho-TPPI gradient selection and decoupling during acquisition of PVAc-1. Spectra were recorded at 298K in $\mathrm{CDCl}_{3}\left(0.02 \mathrm{~g}^{\mathrm{ml}} \mathrm{l}^{-1}\right)$. The blue peaks correspond to methylene groups whereas the red peaks designate methyl or methine moieties.

Head-to-head adducts clearly do not accumulates at the PVAc chain-ends. As stated in the introduction, a possible cause for this result is the absence of head-to-head radical addition in the VAc polymerization carried out in the presence of $\mathrm{Co}(\mathrm{acac})_{2}$. In order to clarify this point, we also analyzed PVAc-2. The larger degree of polymerization for this sample $\left(X_{n} \sim 600\right)$ should increase the relative intensities of any $\mathrm{H}-\mathrm{H}$ addition defects in the backbone compared to the chain-ends functionalities and therefore facilitate their detection. To maximize the signal-tonoise ratio, a concentrated polymer solution in $\mathrm{CDCl}_{3}\left(0.1 \mathrm{~g} \cdot \mathrm{ml}^{-1}\right)$ was used and ${ }^{13} \mathrm{C}$ spectra were recorded with continuous ${ }^{1} \mathrm{H}$ decoupling using a pulse flip angle of $90^{\circ}$. Figure 2 provides a direct comparison between PVAc-2 and PVAc-3. The spectra were normalized to the intensity of the main peaks.

At a first glance, the two spectra appear identical. Besides the intense a-d resonances assigned to carbon atoms of the regular head-to-tail addition pathway, numerous small signals were detected in the methine and methylene regions. The assignment of these peaks was based on previous studies ${ }^{35,36}$ and corroborated by $2 \mathrm{D}$ experiments in this work (see below). The peaks of very low intensity in the ${ }^{13} \mathrm{C}$ spectra (Figure 2) at $\delta 60.5,49.5$ and 48.9 could be assigned respectively to the terminal $-\mathrm{CH}_{2}-\mathrm{OAc}$ methylene group e, the methoxy carbon $\mathbf{g}$ and the methylene group $\mathbf{i}$ of the V-70 initiating fragment. The more intense resonances at $\delta 73.6,70.4$ and 69.5 , were associated to the carbons $\mathbf{m}, \mathbf{l}$ and $\mathbf{p}$, typical of the methine carbons of head-to- 
head-to-tail (HHT) sequences. Examination of the methylene region in both spectra (PVAc-2 by CMRP and PVAc-3 by FRP, in Figure 2) confirmed the presence of $-\mathrm{CH}_{2}$ - signals characteristic of H-H-T units, i.e. peaks $\mathbf{k}(\delta 32.6-36.3), \mathbf{o}(\delta 29.1-31.1)$ and $\mathbf{n}(\delta 68.5-70.3)$.

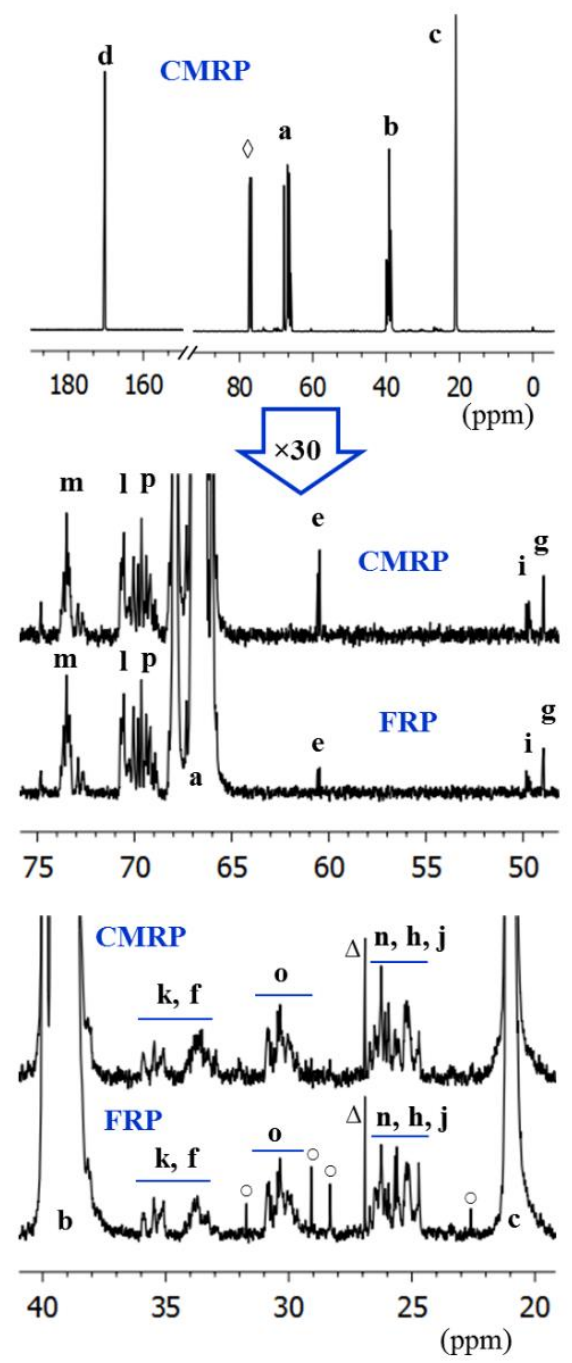

Figure 2. ${ }^{13} \mathrm{C}$ NMR spectra of PVAc-2 and PVAc-3 prepared by CMRP and FRP, respectively. Spectra were recorded at $298 \mathrm{~K}$ in $\mathrm{CDCl}_{3}\left(0.1 \mathrm{~g} \cdot \mathrm{ml}^{-1}\right)$. The assignments of the labeled peaks are given in Chart 1 and chemical shifts are provided as supporting info (see table S1). The overlaid spectra were normalized based on the intensity of the main chain peaks. Traces of solvents were detected: chloroform $(\diamond)$, cyclohexane $(\Delta)$ and heptane $(\circ)$. 
Based on the work of Lovell et al. ${ }^{35,36}$ and on the data collected here for PVAc-1 (see Figure 1), we know that the signals generated by the H-H VAc additions could overlap with other resonances such as those arising from branching on the methyl side groups, or the methyl groups $\mathbf{h}$ and $\mathbf{j}$ of the V-70 initiating fragment. Hence, we performed HSQC measurements on PVAc-2 (Figure 3) and PVAc-3 (Figure S1) in order to isolate the peaks of interest and evaluate the level of defects in each polymer. The HSQC spectrum of PVAc-2 confirmed some overlap of the methylene resonance of the H-H-T sequence with those of the V-70 fragment methyl groups $\mathbf{h}$ and $\mathbf{j}$ at $\delta_{\mathrm{C}} 26$ and with the penultimate signal $\mathbf{k}$ at $\delta_{\mathrm{C}} 33$ (Figure 3). The relative integration between the H-H-T methylene cross-peaks $\mathbf{o}$ and $\mathbf{n}$ with the methylene $\mathbf{b}$ of the main chain suggest that PVAc-2 contains approximately $1.3 \mathrm{~mol} \%$ of inverted VAc units in its backbone. The same conclusion was drawn after comparison of signal $\mathbf{m}$ and $\mathbf{a}$ (1.2 mol\% of H-H-T units) (Figure 3). We have also tried to evaluate the H-H-T content in PVAc-2 by ${ }^{1} \mathrm{H}$ NMR. In spite of some resonance overlap in the ${ }^{1} \mathrm{H}$ spectrum (Figure S2) requiring a difficult deconvolution process, this additional measurement confirms the presence of the $\mathrm{H}-\mathrm{H}$ inverted repeat units in the $1 \mathrm{~mol} \%$ range. The analogous HSQC experiment on PVAc-3 reveals the same level of H-H-T signals (Figure S1). On this basis, we can conclude that the presence of $\mathrm{Co}(\mathrm{acac}) 2$ neither suppresses the head-to-head additions nor changes their relative fraction in the PVAc chain.

The terminal -CH2-OAc e resonance is important for the microstructure analysis, especially for evaluating the level of branching. ${ }^{33}$ This methylene group may result from several processes (see Scheme S1). Termination by disproportionation produces this group in one of the two dead chains. However, this disproportionation is negligible in VAc polymerization because the unreactive 1,2-disubstituted olefinic end group of the other dead chain is not detected. Chain 
transfer to polymer leads to a chain terminated by a - $\mathrm{CH} 2-\mathrm{OAc}$ group and a chain with a radical function on the polymer backbone, leading to branching. Finally, chain transfer to the monomer by $\mathrm{H}$-abstraction reaction from its methyl group produces one $-\mathrm{CH} 2-\mathrm{OAc}$ terminated chain and a

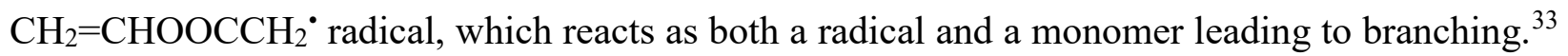
Hence, based on these considerations, Lovell et al. determined a level of branching equal to about $0.1 \mathrm{~mol} \%$ for a PVAc prepared by FRP in bulk at $70^{\circ} \mathrm{C}$ at $30 \%$ of monomer conversion. ${ }^{35}$ In the ${ }^{13} \mathrm{C}$ spectrum of PVAc-3 (Figure 2) the intensity of the e resonance at $\delta_{\mathrm{C}} 60.5$ appears very low. From the relative integrated area of the ${ }^{1} \mathrm{H}$ NMR resonances e (at $\delta_{\mathrm{H}} 4.08$ ) and a (at $\delta_{\mathrm{H}}$ 4.80), PVAc-3 contains about $0.045 \mathrm{~mol} \%$ of branches. Such a low value is reasonable considering the rather low polymerization temperature $\left(40^{\circ} \mathrm{C}\right)$ used for the preparation of PVAc3 and the fact that the level of branching is known to decrease with temperature. ${ }^{35}$

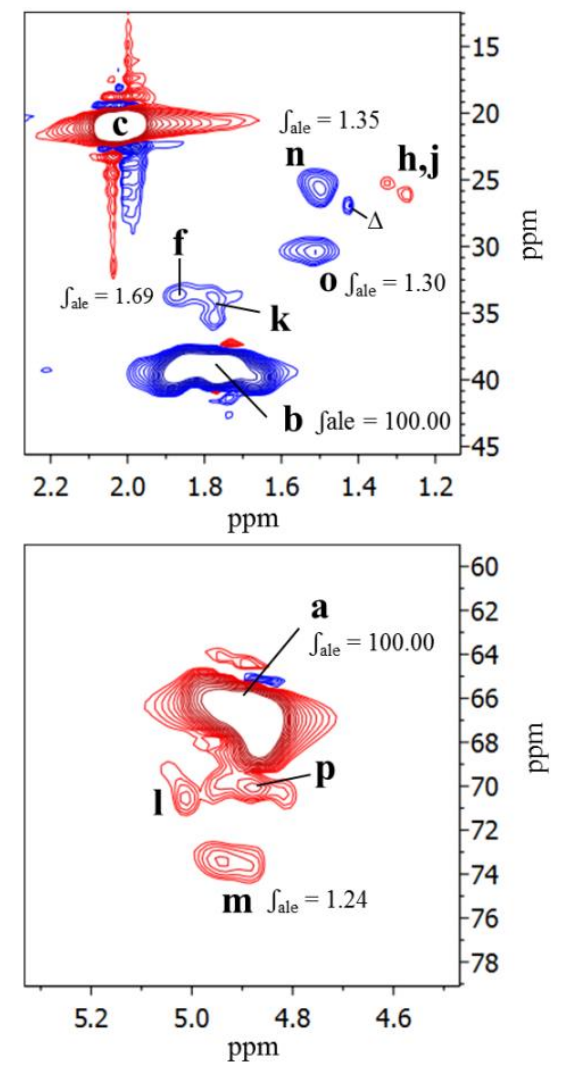


Figure 3. Expanded 2-D edited HSQC spectrum showing the methylene (above) and methine (below) regions of PVAc-2. Spectra were recorded at $298 \mathrm{~K}$ in $\mathrm{CDCl} 3\left(0.1 \mathrm{~g} \cdot \mathrm{ml}^{-1}\right)$. The symbol $(\Delta)$ designates cyclohexane traces. The assignments of the labeled peaks are given in Chart 1 and chemical shifts are provided in Table S1. The blue peaks correspond to methylene groups whereas the red peaks designate methyl or methine moieties.

Interestingly, signal e appears more intense in the ${ }^{13} \mathrm{C}$ spectrum of PVAc-2 than in that of PVAc-3 (see Figure 2). The quantitative analysis for PVAc-2 (Figure S2) revealed that this terminal methylene group represents $0.16 \mathrm{~mol} \%$ of the polymer units. This does not mean that the cobalt complex used in CMRP increases the level of branching, because the $-\mathrm{CH}_{2} \mathrm{OAc}$ groups are also generated by $\mathrm{Bu}_{3} \mathrm{SnH}$ reduction of the regular $\mathrm{H}-\mathrm{T}-\mathrm{Co}$ dormant species without creating any branches. Moreover, considering the very high efficiency of the $\mathrm{Bu}_{3} \mathrm{SnH}$ reaction and the molar mass of PVAc-2, the C-Co chain-end transformation can be considered as the main contribution to resonance e. Branching is thus very limited in PVAc produced by CMRP because this technique operates at moderate temperatures.

Finally, the cobalt(III) complex at the $\omega$-chain-end of the CMRP dormant species presents an available coordination site that can be saturated by donating molecules, including the carbonyl function of ester moieties. This feature often raised questions about the possible modification of the PVAc stereoregularity by the metal. Figure 4 shows expanded regions of DEPT-135 spectra for PVAc-2 and PVAc-3. The resonance assignments were made on the basis of a highresolution spectrometric study by Katsuraya et al. ${ }^{39}$ The perfect overlay of the spectra unambiguously indicates that CMRP produced atactic PVAc and definitely proves that the cobalt complex has no influence on the stereoregularity of the product. 

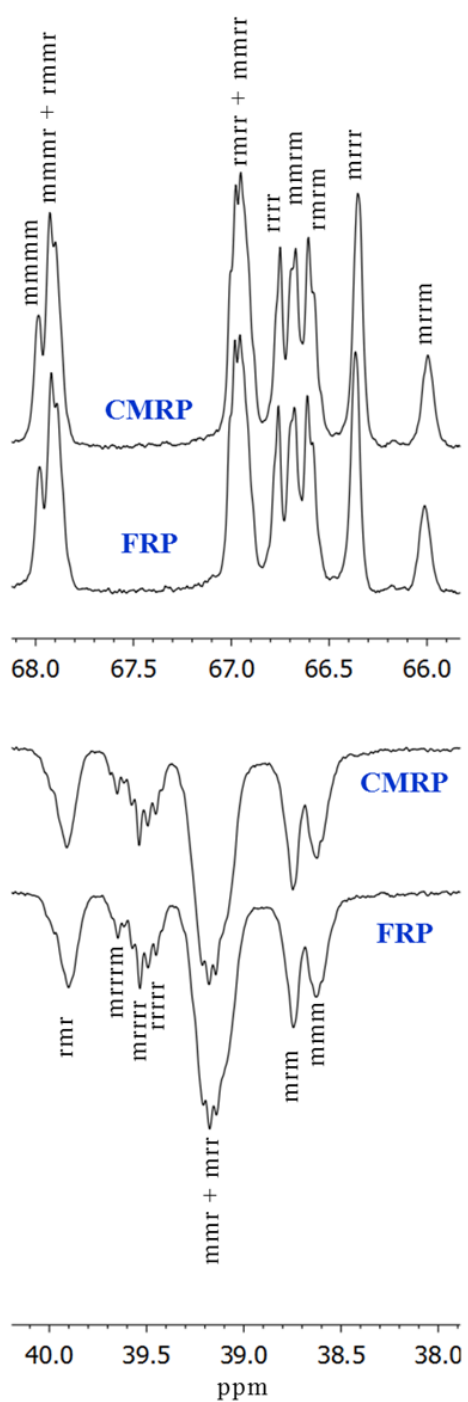

Figure 4. Expanded DEPT-135 spectra showing the methine (above) and methylene (below) regions of PVAc-2 and PVAc-3 prepared by CMRP and FRP, respectively. Spectra recorded at 298K in $\mathrm{CDCl}_{3}\left(0.02 \mathrm{~g} \cdot \mathrm{ml}^{-1}\right)$. The resonance assignment is based on the study by Katsuraya et $a^{39}$

\section{(b) DFT calculations}


The NMR analysis of PVAc made by $\mathrm{Co}(\mathrm{acac})_{2}$-mediated radical polymerization confirmed the presence of the expected fraction of inverted monomer units resulting from head-to-head addition in free radical polymerization. Therefore, the reason for the excellent level of control observed in VAc polymerization until high degrees of polymerization when using this controlling agent must be a rapid reactivation of the dormant species of the latent primary radical, with a rate not too much smaller than the reactivation of the latent secondary radical. This situation contrasts with that of the dormant species in ATRP, ITP, TERP and to a certain extent also RAFT. Alkylcobalt(III) complexes that can be taken as models of each type of dormant species are presently unavailable. Therefore, information on any difference in the reactivation rate is not at reach from experimental investigations. Useful information can only be gathered from theoretical calculations.

The chosen computational model is rather simple. In order to keep the computational cost low without significantly affecting the quality of the result, the polymer structure beyond the last monomer unit at the capped chain end was simplified to an $\mathrm{H}$ atom as shown in Scheme 2. Previous calculations of $\mathrm{M}-\mathrm{X}$ bond strengths for $\mathrm{H}-\mathrm{M}-\mathrm{X}$ and $\mathrm{H}-\mathrm{M}$ '-M-X models $\left(\mathrm{M}, \mathrm{M}^{\prime}=\right.$ monomer; $\mathrm{X}=\mathrm{Cl}, \mathrm{Br}$ ), carried out in order to evaluate penultimate effects in ATRP [M and ${ }^{\prime}$ ' were restricted to propene (P), methyl acrylate (MA) and methyl methacrylate (MMA)] led to the conclusion that a significant change was only present on going from H-MMA-X to H-MMAMMA-X, ${ }^{40}$ which could be mainly attributed to steric destabilization by van der Waals repulsion between the two bulky MMA units. This result confirmed the known penultimate effect in the ATRP of MMA. ${ }^{41}$ Two adjacent VAc monomers should not exert any greater pressure on each other than two MA monomers. Hence, a large penultimate effect is not expected for PVAc and the H-VAc-X BDE should be representative of the BDE in the X-capped PVAc chain. 


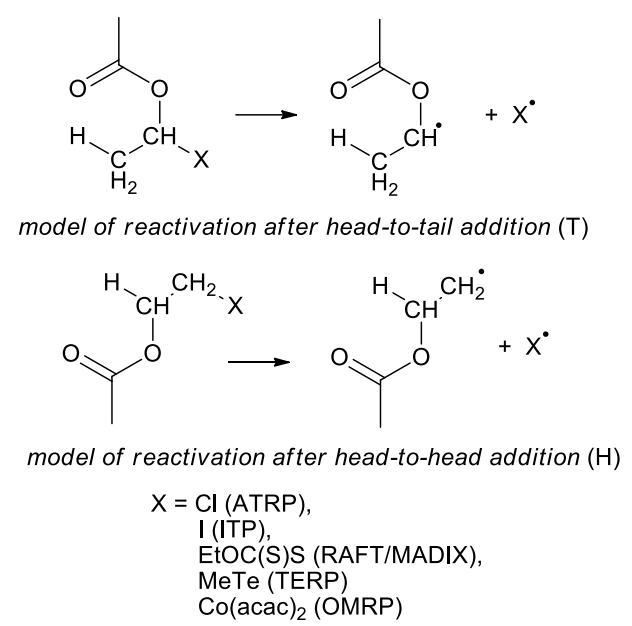

Scheme 2. Models used for the DFT calculations.

For the OMRP system, this bond is directly regulating the activation/deactivation equilibrium. For the ATRP system implicating a $\mathrm{Mt}^{\mathrm{n}}$ catalyst and the corresponding $\mathrm{Mt}^{\mathrm{n}+1}-\mathrm{Cl}$ trapping agent, the equilibrium is related to $\mathrm{BDE}(\mathrm{PVAc}-\mathrm{Cl})-\mathrm{BDE}\left(\mathrm{Mt}^{\mathrm{n}+1}-\mathrm{Cl}\right)$. However, since the latter bond strength is common to the two equilibria, the differences can be evaluated from the individual PVAc-Cl bond strengths, modeled by the $\mathrm{H}-\mathrm{VAc}-\mathrm{Cl}$ isomers. The other three systems (ITP, TERP and RAFT) work on the degenerative transfer principle for which the controlling criterion is different. However, the same $\mathrm{BDE}(\mathrm{HVAc}-\mathrm{X})$ difference is once again relevant to evaluate slowdown effects. This can be easily appreciated from Scheme 3 which illustrates the reactivation of the stronger primary latent radical by the non-degenerative exchange with the secondary active radical. Although in reality the exchange occurs associatively, the enthalpy difference of the process is formally identical to the difference of bond dissociation enthalpies. The greater this difference, the harder to reactivate the dormant species formed after head-tohead addition. 


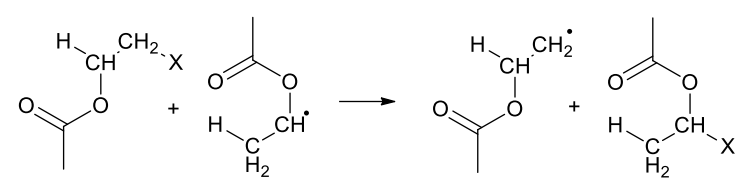

Scheme 3. Reactivation in degenerate exchange

The OMRP system with $\mathrm{X}=\mathrm{Co}(\mathrm{acac})_{2}$ deserves two special comments. Contrary to the other capping agents $\left(\mathrm{Cl}^{\bullet}, \mathrm{I}^{\bullet}, \mathrm{EtOC}(\mathrm{S}) \mathrm{S}^{\bullet}\right.$ and $\mathrm{MeTe}^{\bullet}$ ) that have radical character ( $\mathrm{Co}(\mathrm{acac})_{2}$ complex, which is actually a stable species, ${ }^{42,43}$ is characterized by three unpaired electrons. Otherwise stated, it adopts a spin quartet state $(S=3 / 2)$. When this system binds the radical and generates the alkylcobalt(III) dormant species, the spin changes to zero (diamagnetic). Special care has to be taken in DFT calculations when there is a spin state change, as we have already detailed in previous contributions with calculations of R-Co(acac) 2 BDE. ${ }^{29,31,44-46}$ To summarize, it is known by experience that functionals based on the local density approximation (LDA) and on the generalized gradient approximation (GGA) have a bias in favor of lower spin state and hybrid functionals have a bias in favor of the higher spin state. Special functionals, such as BPW91* which is a hybrid functional where the exact Hartree-Fock exchange contribution is reduced from 25 to $15 \%$, have been developed to cope with this problem. ${ }^{47,48}$ Therefore, we have decided to apply a variety of functionals to span all possible scenarios (BPW91, which is a GGA functional; B3PW91, a popular hybrid functional; the above mentioned BPW91*), including two recently developed functionals (M06, which is a hybrid functional recommended for application in organometallic chemistry ${ }^{49}$ and M06L, a local density functional performing well in transition metal energetics ${ }^{50}$ ). The computational details are given in the SI. 
The second special comment concerns the structure of the polymer chain end for the $\mathrm{Co}(\mathrm{acac})_{2}$-capped PVAc. Given the known preference of low spin $\mathrm{Co}^{\mathrm{III}}$ for an octahedral coordination environment, the 5-coordinate $\mathrm{R}-\mathrm{Co}(\mathrm{acac})_{2}$ tends to bind a 2-electron donor ligand in a position trans to the alkyl group. When sufficiently strong electron donor ligands (L) are present in solution (e.g. $\mathrm{H}_{2} \mathrm{O}$, pyridine, $\mathrm{NEt}_{3}, \mathrm{DMF}$, DMSO), a trans-Co(acac $)_{2}(\mathrm{R})(\mathrm{L})$ complex is formed and, as shown in previous contributions, this phenomenon has profound effects on the polymerization rate and control, ${ }^{25,27}$ as well as on the rate of switch from a PVAc block to the block of another monomer. ${ }^{44}$ In the absence of such donor ligands (e.g. in bulk polymerization; the VAc monomer is not a sufficiently strong donor) then stabilization of the dormant species occurs by chelation involving the carbonyl function of the metal-bonded monomer unit and leading to the formation of a 5-membered ring, see I, Chart $2 .{ }^{13}$ It can therefore be imagined that a similar chelation may occur for the alternative dormant species generated after a head-to-head addition, forming a 6-membered chelate ring, II. For all latent PVAc radicals generated by the other CRP methods, no such chelation is possible.
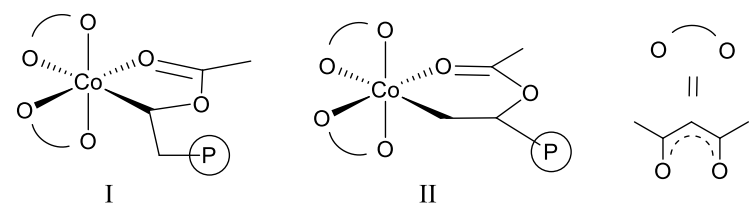

Chart 2. Structure of PVAc-Co(acac $)_{2}$ chain ends.

The enthalpic results of the calculations are summarized in Table 3, whereas figures and Cartesian coordinates of all optimized geometries are provided in the SI. The first line $(\mathrm{X}=$ nothing) shows the enthalpy difference between the two isomeric free radicals. As expected, the 
primary radical $(\mathrm{H}-\mathrm{H})$ is less stabilized than the secondary one $(\mathrm{H}-\mathrm{T})$, the computed difference being relatively independent on the type of functional used in the calculation $(6.6-8.2 \mathrm{kcal} / \mathrm{mol}$ range).

Table 3. Calculated bond dissociation enthalpies $(\mathrm{kcal} / \mathrm{mol})$ of HVAc-X bonds using different functionals. $^{\mathrm{a}}$

\begin{tabular}{|c|c|c|c|c|c|c|}
\hline $\mathrm{X}$ & & BPW91 & BPW91* & B3PW91 & M06 & M06L \\
\hline - & $\Delta^{\mathrm{b}}$ & 8.2 & 7.7 & 7.3 & 7.2 & 6.6 \\
\hline \multirow{3}{*}{$\begin{array}{l}\mathrm{Cl} \\
\qquad \text { (ATRP) }\end{array}$} & $\mathrm{H}-\mathrm{T}$ & 74.2 & 75.7 & 73.9 & 79.4 & 78.7 \\
\hline & $\mathrm{H}-\mathrm{H}$ & 81.8 & 83.0 & 81.0 & 85.8 & 84.0 \\
\hline & $\Delta$ & 7.6 & 7.3 & 7.1 & 6.4 & 5.3 \\
\hline \multirow{3}{*}{$\begin{array}{l}\text { I } \\
\text { (ITP) }\end{array}$} & $\mathrm{H}-\mathrm{T}$ & 47.1 & 46.2 & 46.6 & 54.2 & 51.7 \\
\hline & $\mathrm{H}-\mathrm{H}$ & 56.3 & 55.5 & 55.7 & 62.7 & 59.0 \\
\hline & $\Delta$ & 9.2 & 9.3 & 9.1 & 8.5 & 7.3 \\
\hline \multirow{3}{*}{$\begin{array}{l}\text { MeTe } \\
\text { (TERP) }\end{array}$} & $\mathrm{H}-\mathrm{T}$ & 41.8 & 43.5 & 42.5 & 52.8 & 50.2 \\
\hline & $\mathrm{H}-\mathrm{H}$ & 50.1 & 50.9 & 49.8 & 58.9 & 55.4 \\
\hline & $\Delta$ & 8.3 & 7.4 & 7.3 & 6.1 & 5.2 \\
\hline \multirow{3}{*}{$\begin{array}{l}\text { EtOC(S)S } \\
\text { (RAFT) }\end{array}$} & $\mathrm{H}-\mathrm{T}$ & 46.8 & 51.3 & 50.6 & 57.7 & 54.7 \\
\hline & $\mathrm{H}-\mathrm{H}$ & 52.4 & 56.4 & 55.3 & 61.5 & 57.9 \\
\hline & $\Delta$ & 5.6 & 5.1 & 4.7 & 3.8 & 3.2 \\
\hline \multirow{3}{*}{$\begin{array}{l}\mathrm{Co}(\mathrm{acac})_{2} \\
(\mathrm{OMRP})\end{array}$} & $\mathrm{H}-\mathrm{T}$ & 28.2 & 17.3 & 9.3 & 18.5 & 34.2 \\
\hline & $\mathrm{H}-\mathrm{H}$ & 29.1 & 18.3 & 10.2 & 19.9 & 34.3 \\
\hline & $\Delta$ & 0.9 & 1.0 & 0.9 & 1.4 & 0.1 \\
\hline
\end{tabular}

${ }^{a}$ Values are $\mathrm{BDE}(\mathrm{HVAc}-\mathrm{X})$ in $\mathrm{kcal} / \mathrm{mol} . \mathrm{H}-\mathrm{T}=$ head-to-tail coupling model (secondary radical); $\mathrm{H}-\mathrm{H}=$ head-to-head coupling model (primary radical); $\Delta=\mathrm{BDE}(\mathrm{H}-\mathrm{H})-\mathrm{BDE}(\mathrm{H}-\mathrm{T}){ }^{\mathrm{b}}{ }^{\mathrm{b}} \Delta=$ enthalpy difference between the two isomeric free radicals. 
The BDE(HVAc-X) for each isomer, related to each $\mathrm{X}$ group with radical nature $(\mathrm{S}=1 / 2)$, namely the dormant species in ATRP, ITP, TERP and RAFT, is also quite similar for all functionals that involve the PW91 correlation part, whereas it is slightly higher (by 4-10 kcal/mole depending on X) when using Truhlar's M06 and M06L functionals, with M06 always yielding higher BDEs relative to M06L. The special $\mathrm{Co}(\mathrm{acac})_{2}$ case will be analyzed separately below. The BDE difference $(\Delta)$ between the isomeric bonds is however always in a narrow range (within $3 \mathrm{kcal} / \mathrm{mol}$ ), M06 and M06L always giving slightly smaller differences. These $\Delta$ values are not too different than the enthalpy difference between the isomeric free radicals, which is not totally unexpected. The $\Delta$ values associated to $\mathrm{Cl}$ and MeTe are indeed very close to the enthalpy difference between the isomeric free radicals, whereas they are slightly greater for the ITP dormant species (there is an extra stabilization in the HVAc-I bond for the $\mathrm{H}-\mathrm{H}$ isomer, or a destabilization for the H-T isomer) and slightly smaller for the RAFT dormant species. In the latter case, however, the difference remains relatively high (from $3.2 \mathrm{kcal} / \mathrm{mol}$ at the M06L level to $5.6 \mathrm{kcal} / \mathrm{mol}$ at the BPW91 level), too high to account for an equally rapid reactivation from the dormant species with the primary radical. Nevertheless, the calculations predict that the slowdown effect in RAFT using xanthates should be less pronounced relative to ATRP, TERP, and particularly ITP, in line with the experimental evidence.

The $\mathrm{Co}(\mathrm{acac})_{2}$ case is more interesting, because there is a greater variation of BDE among different functionals, the greatest difference being $25 \mathrm{kcal} / \mathrm{mol}$ for the $\mathrm{T}$ isomer between the calculations with B3PW91 and M06-L. The calculated BDE that are reported in Table 3 are based on the chelated structures shown in I and II (Chart 2) for the dormant species. The greater variation of $\mathrm{BDE}$ between different functionals is caused by the change of spin state on going 
from the $\mathrm{Co}^{\mathrm{III}}$ dormant species ( $\mathrm{S}=0$ ) to the separate fragments $(\mathrm{S}=1 / 2$ for the organic radical and $3 / 2$ for $\mathrm{Co}^{\mathrm{II}}(\mathrm{acac})_{2}$, for a total of $\mathrm{S}=1$ for the antiferromagnetically coupled pair). As expected from the typical performance in problems involving a spin state change, the highest computed $\mathrm{BDE}$ for each isomer is associated with the local M06L functional and, to a lesser extent, with the generalized gradient BPW91 functional, whereas the lowest BDE is given by the hybrid functional B3PW91. The "ad hoc" BPW91* functional yields intermediate BDE values. The M06 functional, although being of hybrid type, yields results closer to those of the "ad hoc" BPW91* functional than to those of the hybrid B3PW91 functional. The most important point, however, is that all functionals yield essentially the same $\Delta$ for the organocobalt(III) dormant species, just like for the other dormant species with the radical-type $\mathrm{X}$ groups.

The point that is now of interest is the very different $\Delta$ for the $\mathrm{Co}(\mathrm{acac})_{2}$-capped polymer chain models (close to zero) relative to the ATRP, RAFT, ITP and TERP dormant chain models. This means that an essentially equivalent energetic cost is predicted for the reactivation of both types of dormant species, comforting the experimental evidence of the absence of slowdown and good control for the $\mathrm{Co}(\mathrm{acac})_{2}$-mediated VAc polymerization, contrary to ATRP, ITP, TERP, OMRP with other metal complexes and to a certain extent RAFT with xanthates. In order to rationalize this large difference in relative stabilization, the radical releasing process has been analyzed in more details to evaluate the individual contributions of the chelation and the intrinsic $\mathrm{Co}^{\text {III-C }}$ BDE. This analysis has only been carried out using the BPW91* functional and the result is graphically shown in Figure 5. Going from $\mathrm{Co}(\mathrm{acac})_{2}$ (in the middle) to the HVAc-Co ${ }^{\mathrm{III}}(\mathrm{acac})_{2}$ dormant species (regular H-T isomer toward the right and inverted $\mathrm{H}-\mathrm{H}$ isomer toward the left), the process can be split into two separate steps: first, bond formation yields a 5-coordinate alkylcobalt(III) intermediate that has a $\mathrm{S}=0$ ground state and a square pyramidal geometry with the 
alkyl group in the apical position. The spin state change occurs in this step. Subsequently, the arrangements of the two acac ligands changes from planar to butterfly, in order to move the empty coordination site from trans to cis relative to the alkyl group and to allow coordination of the carbonyl function. The calculations indicate that the bond formation is more exothermic, as could be anticipated, for the more reactive primary radical $(16.0 \mathrm{kcal} / \mathrm{mol}$ for the $\mathrm{H}-\mathrm{H}$ isomer $v s$. $11.1 \mathrm{kcal} / \mathrm{mol}$ for the $\mathrm{H}-\mathrm{T}$ isomer). The difference of $4.9 \mathrm{kcal} / \mathrm{mol}$ in these intrinsic BDEs is rather similar to that calculated for the RAFT dormant species with the same functional (5.1 $\mathrm{kcal} / \mathrm{mol})$. However, the much more favorable chelation to make a 5 -membered ring for the $\mathrm{T}$ isomer (worth $6.2 \mathrm{kcal} / \mathrm{mol}$ on the enthalpy scale) provides additional stabilization to the H-T dormant species relative to the $\mathrm{H}-\mathrm{H}$ isomer, for which chelation leading to a 6-membered ring is only worth $2.3 \mathrm{kcal} / \mathrm{mol}$ of stabilization. Therefore, the compensation of a weaker bond by a more stable chelate renders the stabilization of the H-T dormant species equivalent to that of the more reactive $\mathrm{H}-\mathrm{H}$ isomer and both dormant species can be reactivated with similar rates. Note that this compensation effect is only possible when the metal complex has the possibility to make a coordination site available for chelation is an adjacent position (cis) to the metal-carbon bond, which is the case for $\mathrm{Co}(\mathrm{acac})_{2}$ and not for other metal complexes such as $\mathrm{CpCr}($ nacnac $) .{ }^{14}$ The porphyrin compound (TMP)Co ${ }^{15}$ equally forbids chelation because of the rigidity of the planar porphyrin ligand. 


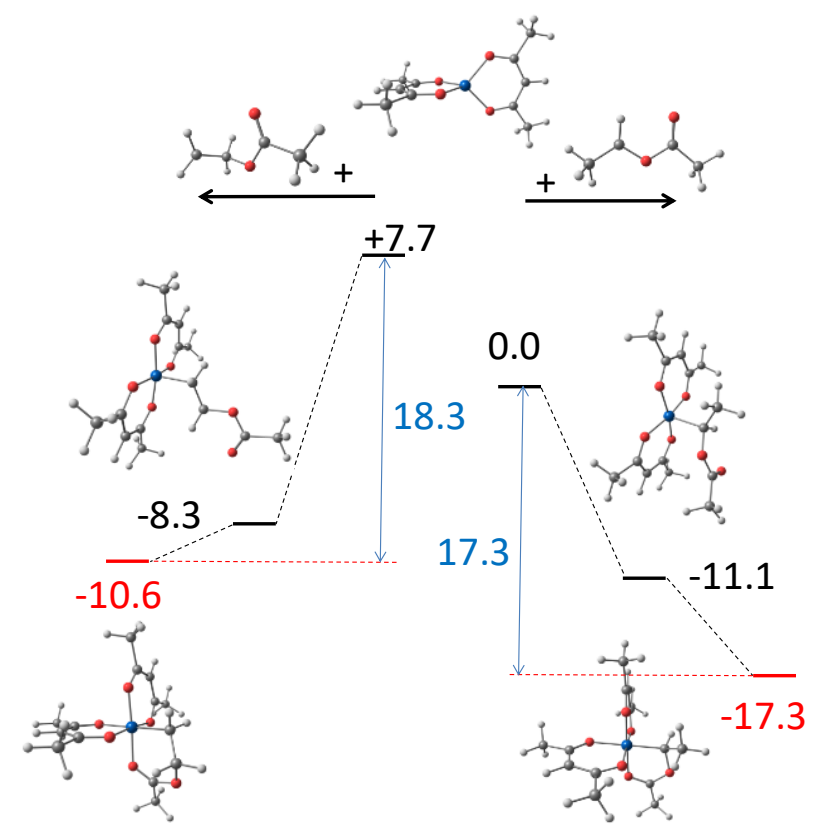

Figure 5. Relative BPW91* enthalpies and optimized geometries of the species implicated in the deactivation process of the $\mathrm{T}$ and $\mathrm{H}$ PVAc radical models by $\mathrm{Co}(\mathrm{acac})_{2}$.

\section{Conclusion}

We have used NMR spectroscopy and computational calculations to gain a comprehensive view of the impact of the inverted head-to-head addition mode in the CRP of vinyl acetate. In general, the primary head-to-head radicals lead to a more stable dormant species compared to the regular secondary head-to-tail adducts that, because of its more difficult reactivation, leads to a slowdown or inhibition of the polymerization and to an increase of the molar mass distribution. However, these problems are not observed for the $\mathrm{Co}(\mathrm{acac})_{2}$-mediated polymerization. A detailed NMR study has revealed a similar fraction of head-to-head sequences in the PVAc produced by CMRP and FRP under the same experimental conditions. This proves that the cobalt complex has no effect on the VAc insertion mode. Moreover, no abnormal accumulation of these repeated units was observed at the chain-end. Therefore, both types of dormant species 
must be reactivated at similar rates. This assumption was corroborated by DFT calculations which predict similar enthalpic stabilizations for the secondary H-T-Co and primary H-H-Co dormant species. The stronger Co-C $\sigma$-bond formed by the $\mathrm{H}-\mathrm{H}$ adduct is compensated by a weaker stabilization from the formation of the 6-membered chelate ring with the carbonyl function of the $\omega$ monomer. On the other hand, the regular H-T-Co dormant species contains a weaker Co-C $\sigma$-bond and a stronger 5-membered chelate ring. The combination of both effects yields a similar reactivation rate from both dormant species. This peculiar structural feature is specific for the $\mathrm{Co}(\mathrm{acac})_{2}$-terminated dormant chains, at variance with the PVAc-X dormant chains of other CRP techniques like ATRP, RAFT/MADIX, ITP and TERP, for which the C-X bond to the primary $\mathrm{H}-\mathrm{H}$ radical is significantly stronger and therefore more difficult to reactivate. The investigation has also highlighted a low degree of branching for the PVAc, resulting from the mild temperatures used for the polymer synthesis.

\section{ASSOCIATED CONTENT}

Experimental section detailing the polymer preparation and analysis, the instrumentation used, the computational details and results (15 pages). This material is available free of charge via the Internet at http://pubs.acs.org.

\section{AUTHOR INFORMATION}

\section{Corresponding Author}

* Fax: +33-561553003; E-mail: rinaldo.poli@1cc-toulouse.fr.

* Fax: +32-43663497; E-mail: adebuigne@ulg.ac.be.

\section{Author Contributions}


The manuscript was written through contributions of all authors.

\section{ACKNOWLEDGMENT}

The Toulouse authors thank the Centre National de la Recherche Scientifique (CNRS), the Institut Universitaire de France (IUF) and the Agence National de la Recherche (project OMRP, grant ANR-2010-BLANC-7101) for financial support of this work. In addition, this work was granted access to the HPC resources of CINES under the allocation 2013-086343 made by GENCI (Grand Equipement National de Calcul Intensif) and to the resources of the CICT (Centre Interuniversitaire de Calcul de Toulouse, project CALMIP). The Liège authors are grateful to the "Fonds National de la Recherche Scientifique" (FRS-FNRS) and to the Belgian Science Policy for financial support in the frame of the Interuniversity Attraction Poles Programme (P7/05)-Functional Supramolecular Systems (FS2) for financial support. A.D. is also grateful for fundings from the University of Liège via the "Fonds spéciaux pour la recherche". A.D., P.D. and C.D. are Research Associate, Senior Research Associate and Research Director of the FRS- FNRS. The authors also thank C. Damblon and M. Bourguignon for skillful assistance.

\section{ABBREVIATIONS}

CRP, Controlled Radical Polymerization; OMRP, Organometallic Mediated Radical Polymerization; CMRP, Cobalt Mediated Radical Polymerization; ITP, Iodine Transfer Polymerization; ATRP, Atom Transfer Radical Polymerization; RAFT/MADIX, Reversible Addition-Fragmentation chain Transfer polymerization/MAcromolecular Design by Interchange of Xanthates; TERP, organoTEllurium mediated Radical Polymerization. 


\section{REFERENCES.}

(1) Cordeiro, C. F.; Petrocelli, F. P. In Encyclopedia of Polymer Science and Technology; Mark, H. F., Kroschwitz, J. I., Bikales, N., Eds.; John Wiley \& Sons: New York, 2004; Vol. 12, p 416-451.

(2) Ito, S.; Munakata, K.; Nakamura, A.; Nozaki, K. J. Am. Chem. Soc. 2009, 131, 1460615607.

(3) Matyjaszewski, K.; Gnanou, Y.; Leibler, L. Macromolecular Engineering: Precise Synthesis, Materials Properties, Applications; Wiley-VCH Verlag GmbH, 2007.

(4) Paik, H.-J.; Teodorescu, M.; Xia, J.; Matyjaszewski, K. Macromolecules 1999, 32, 70237031 .

(5) Xia, J.; Paik, H.-J.; Matyjaszewski, K. Macromolecules 1999, 32, 8310-8314.

(6) Wakioka, M.; Baek, K. Y.; Ando, T.; Kamigaito, M.; Sawamoto, M. Macromolecules 2002, 35, 330-333.

(7) Tang, H. D.; Radosz, M.; Shen, Y. Q. AIChE Journal 2009, 55, 737-746.

(8) Destarac, M.; Charmot, D.; Franck, X.; Zard, S. Z. Macromol. Rapid Comm. 2000, 21, 1035-1039.

(9) Postma, A.; Davis, T. P.; Li, G. X.; Moad, G.; O'shea, M. S. Macromolecules 2006, 39, 5307-5318.

(10) Stenzel, M. H.; Cummins, L.; Roberts, G. E.; Davis, T. P.; Vana, P.; Barner-Kowollik, C. Macromol. Chem. Phys. 2003, 204, 1160-1168.

(11) Iovu, M. C.; Matyjaszewski, K. Macromolecules 2003, 36, 9346-9354.

(12) Kwak, Y.; Goto, A.; Fukuda, T.; Kobayashi, Y.; Yamago, S. Macromolecules 2006, 39, 4671-4679.

(13) Debuigne, A.; Champouret, Y.; Jérôme, R.; Poli, R.; Detrembleur, C. Chem. Eur. J. 2008, 14, 4046-4059.

(14) Champouret, Y.; Macleod, K. C.; Baisch, U.; Patrick, B. O.; Smith, K. M.; Poli, R. Organometallics 2010, 29, 167-176.

(15) Peng, C. H.; Scricco, J.; Li, S.; Fryd, M.; Wayland, B. B. Macromolecules 2008, 41, 2368-2373.

(16) Charmot, D.; Corpart, P.; Adam, H.; Zard, S. Z.; Biadatti, T.; Bouhadir, G. Macromol. Symp. 2000, 150, 23-32.

(17) Rizzardo, E.; Chiefari, J.; Mayadunne, R. T. A.; Moad, G.; Thang, S. H. ACS Symposium Series 2000, 768, 278-296.

(18) Girard, E.; Tassaing, T.; Marty, J. D.; Destarac, M. Polymer Chemistry 2011, 2, 22222230 .

(19) Debuigne, A.; Caille, J. R.; Jérôme, R. Angew. Chem., Int. Ed. 2005, 44, 1101-1104.

(20) Debuigne, A.; Caille, J. R.; Detrembleur, C.; Jerome, R. Angew. Chem., Int. Ed. 2005, 44, 3439-3442.

(21) Debuigne, A.; Caille, J. R.; Willet, N.; Jerome, R. Macromolecules 2005, 38, 9488-9496.

(22) Debuigne, A.; Caille, J.-R.; Jérôme, R. Macromolecules 2005, 38, 5452-5458.

(23) Bryaskova, R.; Detrembleur, C.; Debuigne, A.; Jerome, R. Macromolecules 2006, 39, 8263-8268.

(24) Detrembleur, C.; Debuigne, A.; Bryaskova, R.; Charleux, B.; Jerome, R. Macromol. Rapid Comm. 2006, 27, 37-41. 
(25) Maria, S.; Kaneyoshi, H.; Matyjaszewski, K.; Poli, R. Chem. Eur. J. 2007, 13, 24802492.

(26) Debuigne, A.; Poli, R.; Jérôme, C.; Jérome, R.; Detrembleur, C. Prog. Polym. Sci. 2009, 34, 211-239.

(27) Debuigne, A.; Poli, R.; Jérôme, R.; Jérôme, C.; Detrembleur, C. ACS Symp. Ser. 2009, $1024,131-148$.

(28) Hurtgen, M.; Detrembleur, C.; Jerome, C.; Debuigne, A. Polym. Rev. 2011, 51, 188-213.

(29) Debuigne, A.; Morin, A. N.; Kermagoret, A.; Piette, Y.; Detrembleur, C.; Jérôme, C.; Poli, R. Chem. Eur. J. 2012, 18, 12834-12844.

(30) Detrembleur, C.; Debuigne, A.; Hurtgen, M.; Jerome, C.; Pinaud, J.; Fevre, M.; Coupillaud, P.; Vignolle, J.; Taton, D. Macromolecules 2011, 44, 6397-6404.

(31) Piette, Y.; Debuigne, A.; Jérôme, C.; Bodart, V.; Poli, R.; Detrembleur, C. Polymer Chemistry 2012, 3, 2880-2891.

(32) Gillies, M. B.; Matyjaszewski, K.; Norrby, P.-O.; Pintauer, T.; Poli, R.; Richard, P. Macromolecules 2003, 36, 8551-8559.

(33) Matyjaszewski, K.; Poli, R. Macromolecules 2005, 38, 8093-8100.

(34) Flory, P. J.; Leutner, F. S. Journal of Polymer Science 1948, 3, 880-890.

(35) Britton, D.; Heatley, F.; Lovell, P. A. Macromolecules 1998, 31, 2828-2837.

(36) Britton, D.; Heatley, F.; Lovell, P. A. Macromolecules 2000, 33, 5048-5052.

(37) Vercauteren, F. F.; Donners, W. a. B. Polymer 1986, 27, 993-998.

(38) Ahmad, N. M.; Charleux, B.; Farcet, C.; Ferguson, C. J.; Gaynor, S. G.; Hawkett, B. S.; Heatley, F.; Klumperman, B.; Konkolewicz, D.; Lovell, P. A.; Matyjaszewski, K.; Venkatesh, R. Macromol. Rapid Comm. 2009, 30, 2002-2021.

(39) Katsuraya, K.; Hatanaka, K.; Matsuzaki, K.; Yamaura, K. Macromol. Rapid Comm. 2000, 21, 697-700.

(40) Lin, C. Y.; Coote, M. L.; Petit, A.; Richard, P.; Poli, R.; Matyjaszewski, K. Macromolecules 2007, 40, 5985-5994.

(41) Nanda, A. K.; Matyjaszewski, K. Macromolecules 2003, 36, 8222-8224.

(42) Cotton, F. A.; Soderberg, R. H. Inorg. Chem. 1964, 3, 1-5.

(43) Cotton, F. A.; Elder, R. C. Inorg. Chem. 1965, 4, 1145-1151.

(44) Debuigne, A.; Michaux, C.; Jérôme, C.; Jérôme, R.; Poli, R.; Detrembleur, C. Chem. Eur. J. 2008, 14, 7623-7637.

(45) Debuigne, A.; Poli, R.; De Winter, J.; Laurent, P.; Gerbaux, P.; Dubois, P.; Wathelet, J.P.; Jérôme, C.; Detrembleur, C. Chem. Eur. J. 2010, 16, 1799-1811.

(46) Debuigne, A.; Poli, R.; De Winter, J.; Laurent, P.; Gerbaux, P.; Wathelet, J.-P.; Jérôme, C.; Detrembleur, C. Macromolecules 2010, 43, 2801-2813.

(47) Reiher, M. Inorg. Chem. 2002, 41, 6928-6935.

(48) Harvey, J.; Aschi, M. Faraday Disc. 2003, 124, 129-143.

(49) Zhao, Y.; Truhlar, D. G. Theor. Chem. Acc. 2008, 120, 215-241.

(50) Zhao, Y.; Truhlar, D. G. J. Chem. Phys. 2006, 125, 194101. 


\section{TABLE OF CONTENT GRAPHIC.}

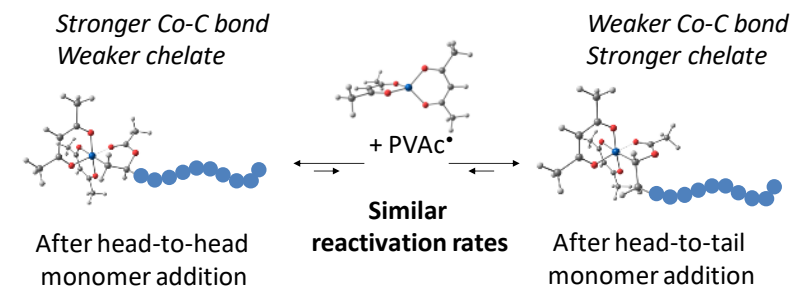

